\title{
Negotiation Support in Collaborative Services Design
}

\author{
Ana Inês Oliveira ${ }^{1,2}$ and Luis M. Camarinha-Matos ${ }^{1,2}$ \\ ${ }^{1}$ CTS, Uninova, 2829-516 Caparica, Portugal \\ ${ }^{2}$ Faculdade de Ciências e Tecnologia, Universidade Nova de Lisboa, Campus da Caparica, \\ Quinta da Torre, 2829-516 Monte Caparica, Portugal \\ \{aio, cam\}@uninova.pt
}

\begin{abstract}
Due to the continuous changes in markets and society, companies and organizations have to constantly adapt themselves to maintain competitiveness. One of the options is to strategically join their competencies to rapidly respond to a business or collaboration opportunity through a goaloriented network. Nevertheless, as market demands are continuously and fast evolving, besides taking advantage of clustering themselves, companies and organizations have to find better solutions to meet the customer needs. In this context, this paper presents an approach based on a negotiation support environment that enhances the design of new business services under a collaborative perspective, so that the customer's requirements can be better fulfilled.
\end{abstract}

Keywords: Collaborative Network, Negotiation Support Environment, Business Services, Co-Design, Service Co-Creation Network, Service Design.

\section{Introduction}

During the last decade, in manufacturing and service industries, collaboration among small and medium enterprises (SMEs) has focused on competencies and resources sharing as an approach to both create new competitive environments, as well as achieve agility to rapidly answer market demands. Working in collaboration implies on one hand sharing the opportunities and gained profits, but on the other hand also sharing the risks and losses, which in turn increases the survival chances of SMEs. Moreover, one market trend is to have more and more customizable products, so companies are forced to change their paradigm from mass-produced products towards highly customized products and ultimately one-of-a-kind products [1]. This trend is reflected in the term mass-customization that refers to products and services which meet the needs/choices of each individual customer with regards to the variety of different product features.

In GloNet project [2] the design, development and deployment of an agile virtual enterprise environment for networks of SMEs involved in highly customized and service-enhanced products through end-to-end collaboration with customers and local suppliers (co-creation of products and business services) is envisaged [1]. Collaboration among manufacturers, customers and local suppliers can be improved if a methodological approach is followed to design new business services to enhance the 
existing products. This leads to the notion of co-design, where all relevant stakeholders are collectively involved in the design process of a new service [3]. In addition, to support the network of partners (a virtual organization, VO) in achieving agreements during the design of a new business service, it is desirable to have a negotiation environment that facilitates collaboration, and decreases the risks and amount of time spent in this process. The achieved agreements will be the basis for the implementation of the designed service $[4,5]$.

Considering this background and a virtual organization breeding environment (VBE) [6] context, that supports and fosters the creation of dynamic VOs, one relevant research question that emerges is:

How can an electronic negotiation support environment increase the agility in the creation process of successful dynamic virtual organizations?

One important motivation for this work is that by contextualizing the design of a new business service in a collaborative environment, it can also use the same negotiation support environment mechanisms to reach agreements, as the ones that are used for the VO creation process in the VBE environment. Therefore, in order to give an answer to this assumption, this paper presents a service co-design negotiation support system that is being designed and developed in the scope of the GloNet project and part of a $\mathrm{PhD}$ research work. The paper is then organized as follows: Section 2 identifies the relationship to collective awareness systems; Section 3 gives a brief overview of related literature namely on business services and services composition, the GloNet co-creation network characteristics, and service design; Section 4 illustrates the service co-design negotiation support system; and Section 5 presents the conclusions and future work.

\section{Relationship to Collective Awareness Systems}

Collective awareness systems refer to systems that intend to interrelate several sources of data and provide users with relevant data so that they can take better informed and sustainable decisions [7]. These systems harness concepts from other fields such as: the Internet of Things for data collection; Social Networks for interactions; and Wikis for the coproduction of new knowledge.

As previously mentioned, in the manufacturing and service industry, the trend is to move towards a global networked economy, being therefore important to build a collective network context awareness so that it is possible to share business, knowledge and collaboration. With this support it is possible to build alliances to develop creativity [8]. Considering the co-design of new business services where different and diverse stakeholders (including the customer) intervene in the process to achieve new business services design, the collective awareness systems appear with relevance once they can take more accurate and innovative decisions based on the environmental collected data.

\section{Context and Related Areas}

To contextualize the service co-design negotiation support, this section gives a brief overview of related literature. 
Business Services and Composite Business Services. A business service refers to an organized set of added value activities from a business perspective [9], considering issues such as the delivery conditions, service level agreements, period, availability, etc. [1]. It corresponds to the service provided to the customer, and can be implemented by manual services and/or software services whose flow that can be modeled in different business process. Business services delivered to the customer can be composed of several atomic business services. The service providers of such business services together can form a virtual organization to deliver the composite business through a new entity that is the service integrator (that acts as the service provider of the composite business service) [10]. In GloNet, the design of new business services can include this composition of services.

GloNet Co-creation Network. One of the relevant business scenarios identified in GloNet is aimed at providing an environment that supports and promotes the collaborative design of business services. It includes the aspects of mass customization as well as the emergence of new products and solutions to identified needs, through collaboration between manufacturers, customer and members of the customer's community [1]. Therefore, this network (that is a VO) aims at co-design and co-innovate new value-added services for products. During the life-time of a certain product, several service co-creation networks might be created depending on the number of times new promising business ideas come up for new services [11]. Also, an analysis of the IT implementation requirements of those business applications can be performed [12]. This network shall be based on a collaboration environment that helps designing and providing business services based on innovation, knowledge and customer orientation, through collaboration between the different stakeholders (manufacturers, customer and members of the customer's community - open innovation approach).

Service Design. It is an interdisciplinary area that connects all relevant stakeholders in the design of services through some methodological approach [13]. Service design aims at designing user-oriented services making them useful, effective and different from existing ones. It potentiates co-creation between the different users of a service, and the providers [14]. In the different service design activities, especially in cocreation, not all stakeholders need to be involved at the same time; they can be involved just in the specific moments or situation in which they take part [3], which applies to the co-creation and co-design case of GloNet. There are a number of methods and tools for service design that have been emerging [15]; some of which can be found in http://www.servicedesigntools.org/. Nevertheless, some of these tools are just manual methods to organize a collaborative process, others use software tools, but no integrated environment is available, neither any integration between service design and service delivery environments is available. GloNet project is not focused on designing business services but rather on creating a collaborative environment where new multi-stakeholder services can emerge and be provided.

\section{Research Contribution and Innovation}

Negotiation in collaboration plays an important role as it can provide a support environment for the formation of VOs $[6,16,17]$, and essentially improve the entire process of establishing a VO agreement that can lead to the governing rules and 
principles of the consortium during the operation phase. When designing new business services, there is already a consortium (acting like a VO) with the aim of reaching agreements on the design requirements of the new business service. Therefore, a negotiation support environment can contribute to boost the participation in the business service design, namely if the decision making process is fundamentally made by human actors. This is done by providing them with support functionalities, specifically: basic collaboration, data storage, editing, templates management, notary and traceability. As such, there are similarities to a negotiation support environment for the VO formation phase as already supported in the current $\mathrm{PhD}$ research work $[4,5,18]$. As a result, the current work on negotiation support for the design of new business services also supports the adopted research hypothesis:

The process of creating dynamic virtual organizations can become more agile if an appropriate electronic negotiation wizard environment is established with the necessary soft modeling characteristics to structure and conduct the entire negotiation process, making it traceable, reducing the collaboration risks, and managing the participants' expectations. Moreover, the negotiation environment should be customizable according to different collaboration levels, either in terms of commitment or in terms of duration.

Nevertheless, the negotiation support environment for the design of new business services, represents a different collaboration level and improves the entire process of reaching agreements on the design of new business services so that they can be properly developed and/or implemented. To design new business services, a service design methodology has been adopted [18]. As mentioned, a number of methods and tools for service design can be found in different disciplines and for different purposes [15]. Nevertheless, most of the tools are simply manual methods to organize collaboration processes. In GloNet, the aim is to use a service design methodology and adapt it to a philosophy of co-design where new business services can be designed in a collaborative environment with multi-stakeholders and customer involvement. The main steps of the approach are summarized in Table 1.

Table 1. Service Design Methodology in co-creation teams

\begin{tabular}{r|l|l}
\hline \multicolumn{2}{c|}{ Service Design steps } & \multicolumn{1}{c}{ Description } \\
\hline 1 & Identify needed service & $\begin{array}{l}\text { Brainstorming exercise involving an analysis of the needs and } \\
\text { characteristics of the customer. }\end{array}$ \\
\hline 2 & Design touchpoints diagram & To identify user interaction points with the service. \\
\hline 4 & Design blueprint diagram & $\begin{array}{l}\text { To describe the nature and the characteristics of the service } \\
\text { interaction in enough detail to verify, implement and maintain it. It } \\
\text { includes: temporal order, timings, and line of visibility (denoting } \\
\text { what the customer sees and back-office). }\end{array}$ \\
\hline 5 & Service prototyping & $\begin{array}{l}\text { A tool derived from the cinematographic tradition; it is the } \\
\text { representation of use cases through a series of drawings or textual } \\
\text { description, put together in a narrative sequence that illustrates a } \\
\text { sequence of events such as a customer journey. }\end{array}$ \\
\hline
\end{tabular}


For this purpose, it is therefore important to identify: who are the participants; the touchpoints with the customer; and how the participants can share information and documentation between them. Table 2 below addresses some of the relevant characteristics of service design and how they are related to GloNet co-design.

Table 2. Service Design Methodology in co-creation teams

\begin{tabular}{|c|c|c|}
\hline & Service Design relevant characteristics & Relevance for co-creation teams \\
\hline Participants & $\begin{array}{l}\text { Service design assumes the involvement } \\
\text { of various participants from different } \\
\text { backgrounds and specially the } \\
\text { interaction with the customer. }\end{array}$ & $\begin{array}{l}\text { Co-creation of a new service is expected to } \\
\text { involve a temporary collaborative network } \\
\text { (VO), including different stakeholders, from } \\
\text { geographically dispersed manufacturers, to } \\
\text { the providers and supporting institutions } \\
\text { close to the customer. The customer is also } \\
\text { an active part. }\end{array}$ \\
\hline TouchPoints & $\begin{array}{l}\text { In service design it is particularly } \\
\text { relevant to identify the customer journey } \\
\text { in the process of receiving the service, } \\
\text { and thus the points of interaction with } \\
\text { the service provider. }\end{array}$ & $\begin{array}{l}\text { Aiming user-centered services and being the } \\
\text { customer an active part of co-design, it is } \\
\text { very important to consider his interactions } \\
\text { with the service, namely the moments and } \\
\text { places that he gets into direct contact with } \\
\text { the service. }\end{array}$ \\
\hline Sharing & $\begin{array}{l}\text { Service design methods, even if not } \\
\text { supported by software tools, a shared } \\
\text { space where all participants can } \\
\text { visualize the progression of the design } \\
\text { process is assumed. }\end{array}$ & $\begin{array}{l}\text { Collaborative environment where the } \\
\text { involved participants can interact in the } \\
\text { design and creation processes and reach } \\
\text { agreements. }\end{array}$ \\
\hline
\end{tabular}

Service Co-design Negotiation Support System. The Services Co-Design Negotiation Support (CoDeN) system is intended to provide a collaborative environment for design of new business services where the various involved participants can reach agreements on what is decided. The involved participants (including the customer) in this process are defined a priori. Similar to a negotiation support system for VO creation [18], this system is also intended to generate an agreement that represents the reached consensus. Nevertheless, unlike the VO formation negotiation, here there are no free negotiation topics. Instead, the consensus that has to be reached based on the service design methodology that serves as a guide for the negotiation. Examples of available templates can be found in [19]. Similar to other VOs, the entire process is conducted by the VO Planner that acts as the co-creation team mediator.

In Fig. 1, the main flow and interactions of the system are illustrated. The thick arrows represent the strong negotiation that is required in the co-design process and the numbers correspond to the steps of the approach summarized in Table 2. Also, this system directly interacts with: the negotiation support for agreement establishment that allows clients to exchange information with warranty of authenticity and validity as well as providing a safe repository for saving and requesting documentation. 


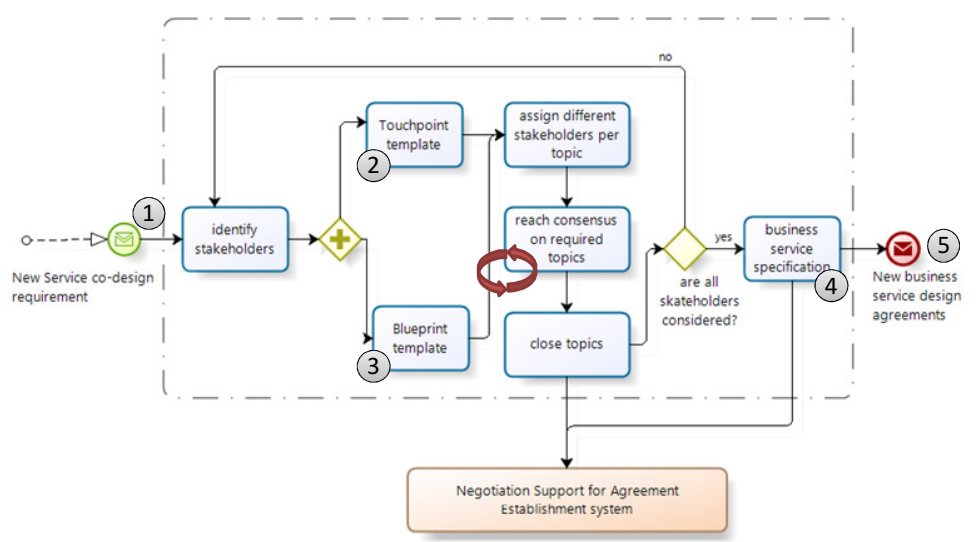

Fig. 1. Services co-design negotiation support system interactions

Below there is an adapted $i^{*}$ Rationale Strategic model where the involved actors as well as their dependency objectives with the system are illustrated. Within the boundaries of the Services Co-Design Negotiation Support system the respective tasks and sub-tasks are presented. The services that directly interact with the involved actors and other related systems are also depicted.

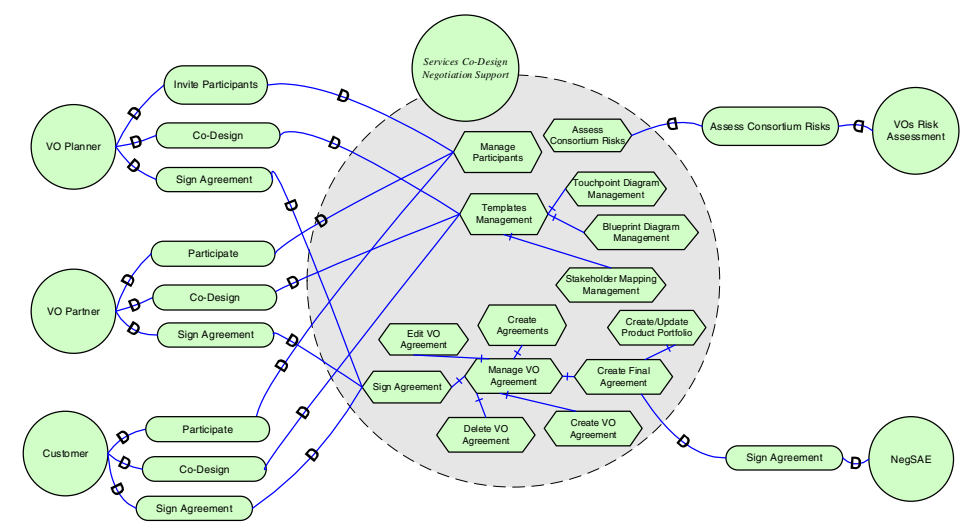

Fig. 2. Adapted $i^{*}$ Rationale Strategic Model for the Services Co-Design Negotiation Support system

Discussion of Results. The work presented in this paper is the result of a service codesign negotiation support system specification aimed at supporting the co-creation team mediator in the negotiation process of a new business service design. The support environment to achieve agreements on the business service design is based on software system that assists the human decision making and guides the generation of 
the final agreement (based on specific templates), and stores the participants' received input. In this way, the process becomes structured and traceable. Moreover, the intended environment is based on the same mechanism already specified for negotiation during a VO formation phase, meaning that it has to be adaptable to different types of collaboration. Through the interaction with other systems, namely: (i) support for agreement establishment, it is also possible to guarantee a degree of authenticity; and (ii) VO risks assessment is possible to reduce the risks in collaboration and increase adaptation to unexpected events because partners expectations are also considered. Through the on-going $\mathrm{PhD}$ research and participation in the European research project GloNet, the topic of new business service design gains more significance. Therefore, the test bed and validation of the current work is being considered in this context.

\section{Conclusions and Further Work}

To compete in the global market, where customer's requirements are becoming more specific and customizable, it is important that companies maintain efficiency and the sustainability level, so they tend to collaborate in order to accomplish those requirements of almost one-of-a kind products or services. One factor that is important is the agility that these companies can have to interoperate and co-work with each other in a co-creation environment. In order that the co-creation or codesign of a new business service becomes more feasible, it is important to have an advanced service to support the existing team, so that the negotiation process to establish agreements can be achieved. This paper summarizes an on-going research work that tries to fulfill the above requirements: the specification of the service codesign negotiation support system. As some of the concepts and preliminary results have already been positively validated, it is now foreseen to achieve a more advanced environment that comprehends most of the described areas with the needed adaptations to support the aimed negotiation support for dynamic VOs creation and new business services design. The emphasis of the current work is on the relations and interactions of the several sub-systems that together provide an advanced consortia formation support, namely: (i) the basic services for VO creation that are related to the order characterization and partners search; (ii) the base negotiation support with negotiation templates management and support for agreement establishment; and (iii) functionalities to reduce potential risks in collaboration. The ongoing validation process is intended to consist in peer validation and supported by the EU project GloNet.

Acknowledgments. This work has been supported by the Collaborative Networks and Distributed Industrial Systems Research Group of Uninova and partly by the GloNet project (FP7 programme) funded by the European Commission. 


\section{References}

1. Camarinha-Matos, L., et al.: Collaborative Business Scenarios in a Service-Enhanced Products Ecosystem. In: Collaborative Networks in the Internet of Services, pp. 13-25. Springer (2012)

2. Camarinha-Matos, L.M., Afsarmanesh, H., Koelmel, B.: Collaborative networks in support of service-enhanced products. In: Camarinha-Matos, L.M., Pereira-Klen, A., Afsarmanesh, H. (eds.) PRO-VE 2011. IFIP AICT, vol. 362, pp. 95-104. Springer, Heidelberg (2011)

3. Sanders, E.B.-N., Stappers, P.J.: Co-creation and the new landscapes of design. Co-design 4(1), 5-18 (2008)

4. Oliveira, A.I., Camarinha-Matos, L.M., Pouly, M.: Agreement negotiation support in virtual organisation creation-an illustrative case. Production Planning \& Control 21(2), 160-180 (2010)

5. Oliveira, A.I., Camarinha-Matos, L.M.: Negotiation Support and Risk Reduction in Collaborative Networks. In: Camarinha-Matos, L.M., Tomic, S., Graça, P. (eds.) DoCEIS 2013. IFIP AICT, vol. 394, pp. 15-24. Springer, Heidelberg (2013)

6. Camarinha-Matos, L., Afsarmanesh, H.: A framework for virtual organization creation in a breeding environment. Annual Reviews in Control 31(1), 119-135 (2007)

7. Sestini, F.: Collective Awareness Platforms: Engines for Sustainability and Ethics. IEEE Technology and Society Magazine 31(4), 54-62 (2012)

8. Di Maio, P., Ure, J.: An open conceptual framework for operationalising collective awareness and social sensing. In: Proceedings of the 3rd International Conference on Web Intelligence, Mining and Semantics. ACM (2013)

9. Brentani, U.: Innovative versus incremental new business services: different keys for achieving success. Journal of Product Innovation Management 18(3), 169-187 (2001)

10. Camarinha-Matos, L.M., et al.: Collaborative Business Services Provision. In: ICEIS 2013 - 15th Int. Conf. on Enterprise Information Systems, Angers, France (2013)

11. Camarinha, L.M., et al.: Supporting product-servicing networks. In: IESM 2013 - 5th Int Conf. on Industrial Engineering and Systems Management. IEEE Explore, Rabat (2013)

12. Yang, S., Zhang, S., Kong, L.: Research on the cooperative decision of business application needs in IT governance. In: 2012 IEEE 16th International Conference on Computer Supported Cooperative Work in Design (CSCWD). IEEE (2012)

13. Mager, B., Sung, T.: Special issue editorial: Designing for services. International Journal of Design 5(2), 1-3 (2011)

14. Sandberg, F.: Co-creating collaborative food service opportunities through work context maps. In: Proceedings of 3rd Service Design and Service Innovation Conference, ServDes. Linköping Electronic Conference Proceedings, vol. 67. Linköping University Electronic Press, Linköping (2012)

15. Wild, P.J.: Review of Service Design Methods. In: IPAS Project Deliverable I15.6. University of Cambridge, Cambridge (2009)

16. Stelmach, M., et al.: Distributed contract negotiation system for virtual organizations. Procedia Computer Science 4, 2206-2215 (2011)

17. Picard, W., Rabelo, R.J.: Engagement in collaborative networks. Production Planning \& Control: The Management of Operations 21(2), 101-102 (2010)

18. Oliveira, A.I., Camarinha-Matos, L.M.: Electronic Negotiation Support Environment in Collaborative Networks. In: Camarinha-Matos, L.M., Shahamatnia, E., Nunes, G. (eds.) DoCEIS 2012. IFIP AICT, vol. 372, pp. 21-32. Springer, Heidelberg (2012)

19. Namahn, Window, Y.: Service Design Toolkit (2013), http: / /www. servicedesigntoolkit.org/ (November 07, 2013) 